\title{
Effect of a topical copper indomethacin gel on inflammatory parameters in a rat model of osteoarthritis
}

This article was published in the following Dove Press journal:

Drug Design, Development and Therapy

12 March 2015

Number of times this article has been viewed

\author{
Nemat Z Yassin' \\ Siham M El-Shenawy' \\ Rehab F Abdel-Rahman' \\ Mostafa Yakoot ${ }^{2}$ \\ Mohamed Hassan ${ }^{3}$ \\ Sherine Helmy ${ }^{4}$ \\ 'Department of Pharmacology, \\ National Research Center, \\ Cairo, Egypt; ${ }^{2}$ Green Clinic and \\ Research Center, Alexandria, Egypt; \\ ${ }^{3}$ Department of Chemistry, Faculty \\ of Science, Alexandria University, \\ Alexandria, Egypt; ${ }^{4}$ European \\ Egyptian Pharmaceutical Industries, \\ Alexandria, Egypt
}

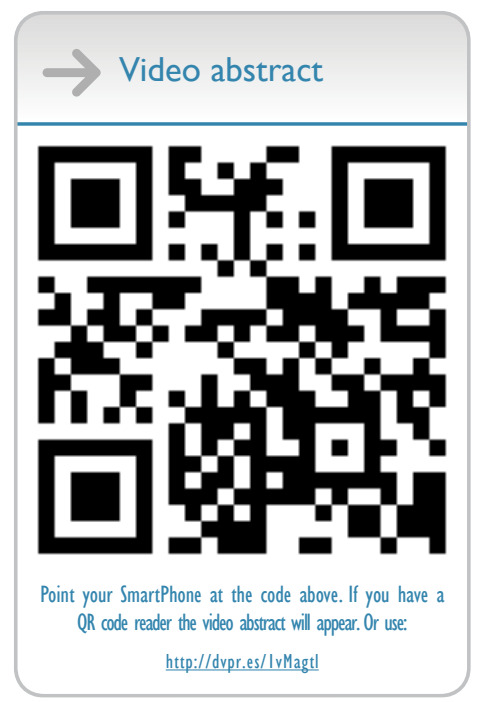

Correspondence: Mostafa Yakoot Green Clinic and Research Center, 27 Green Street, Alexandria 21 I21, Egypt Tel +20339 l 3725

Emailyakoot@yahoo.com
Objective: We aimed to investigate the effect of topical application of a Copper indomethacin (Cu-Indo) gel preparation on monosodium iodoacetate (MIA) induced arthritis of the knee joint of rats and to test our hypothesis that copper complex of indomethacin could be a more potent anti-inflammatory agent than its parent compound.

Methods: After induction of osteoarthritis by the intracapsular injection of $50 \mu \mathrm{L}$ with $40 \mathrm{mg} / \mathrm{mL}$ MIA, we compared the anti-inflammatory efficacy and safety of a topical application of $1 \%$ indomethacin gel in a dose of $1 \mathrm{~g} / \mathrm{kg}$ of the gel (equivalent to $10 \mathrm{mg} / \mathrm{kg}$ of the active substance) daily for 3 weeks versus three decremental dose levels of $\mathrm{Cu}$-Indo gel: an equivalent dose, half the dose, and $25 \%$ of the dose of indomethacin. Anti-inflammatory efficacy was assessed in all treated groups by measurement of serum inflammatory cytokines: interleukin 6 , interleukin 8 , and tumor necrosis factor alpha; and by the weekly assessment of knee joint swelling. Joint mobility and motor coordination were also assessed once weekly by the accelerating rotarod apparatus; histopathological examination of affected joints was also performed. Safety of topical application of $\mathrm{Cu}$-Indo $(0.25,0.5$, and $1 \mathrm{~g} / \mathrm{kg})$ for up to 3 months to rats' skin was determined by the estimation of a complete blood count, liver and kidney functions, and histopathologic examination for target tissues.

Results: $\mathrm{Cu}$-Indo gel at lower doses was superior to or at least as effective as its parent substance, indomethacin, in most of the studied parameters of inflammation. The lowest tested dose of $\mathrm{Cu}$-Indo, corresponding to $25 \%$ of the parent substance indomethacin, exhibited the highest efficacy in reducing the elevated serum-tested interleukins and in increasing the time of duration on the rotarod test, whereas its effect on reduction of edema and tumor necrosis factor alpha was comparable to that of the others. After 3 months of daily application, there were no notable changes in studied safety parameters with the lowest $\mathrm{Cu}$-Indo dose, but the group treated with the higher dose showed a small but statistically significant increase in serum-unconjugated bilirubin and a slight decrease in hemoglobin levels, red blood cells, and platelet count, with normal indices denoting a slight hemolytic effect at the highest dose.

Conclusion: $\mathrm{Cu}$-Indo gel has potent anti-inflammatory activity against joint inflammation in the MIA-treated rat model of osteoarthritis at doses of $0.25,0.5$, and $1 \mathrm{~g} / \mathrm{kg}$. The lowest studied dose was better on both safety and efficacy parameters.

Keywords: osteoarthritis, copper indomethacin gel, monosodium iodoacetate, rats

\section{Introduction}

Osteoarthritis (OA) is a potentially debilitating disorder that can place serious limitations on patient functionality and overall quality of life. ${ }^{1}$ Because there are no curative or disease-modifying therapies for patients with OA at this time, current approaches to management strive to relieve pain and increase functionality while minimizing the potential for adverse effects. ${ }^{2}$ The nonsteroidal anti-inflammatory drugs (NSAIDs) are 
the most frequently used medicines to treat OA as a result of their having both analgesic and anti-inflammatory properties. NSAIDs are commonly taken orally, but they are also available in topical preparations to be applied to or rubbed onto the skin of a painful joint, typically one affected by arthritis, with the aim of relieving pain locally. Indomethacin is a nonselective NSAID that has been shown to be an effective treatment for OA in placebo-controlled trials. $^{3}$

Copper complexes of NSAIDs have been the main interest of many investigators for more than 30 years, but the field is still open for more work to try to answer some unresolved questions. Many comprehensive reviews report a higher efficacy of copper complexes than their parent compounds to reduce symptoms of chronic inflammation, especially adjuvant arthritis, in laboratory animals., ${ }^{4,5}$

Copper indomethacin complex $\left[\mathrm{Cu}_{2}-(\text { Indo })_{4}\left(\mathrm{OH}_{2}\right)_{2}\right]$. $1.5 \mathrm{H}_{2} \mathrm{O}(\mathrm{Cu}-\mathrm{Indo})$ is a $\mathrm{Cu}(\mathrm{II})$ complex of the parent NSAID indomethacin. We suggested that because of its positive redox potential, copper adds to the anti-inflammatory power of indomethacin. ${ }^{6}$

We planned this study to evaluate the efficacy and safety of $\mathrm{Cu}$-Indo topical gel as an anti-inflammatory drug in the treatment of OA, using a monosodium iodoacetate (MIA)induced arthritis rat model.

To test our hypothesis that copper complex of indomethacin could be a more potent anti-inflammatory than its parent compound, and that it can provide efficacy at lower dose levels, we compared the effect of topical $1 \%$ indomethacin gel at a dose of $1 \mathrm{~g} / \mathrm{kg}$ of the gel (equivalent to $10 \mathrm{mg} / \mathrm{kg}$ of the active substance) daily for 3 weeks versus three decremental dose levels of $\mathrm{Cu}$-Indo gel: an equivalent dose, half the dose, and $25 \%$ of the dose of indomethacin as a gel/active substance.

\section{Materials and methods}

\section{Animals}

Male and female Wister rats weighing 130-150 g body weight were used. Standard laboratory food and water were provided ad libitum. Animal procedures were performed in accordance with the regulations of the Ethics Committee of the National Research Centre and followed the recommendations of the National Institutes of Health Guide for Care and Use of Laboratory Animals. Rats were acclimated for 5 days before test, fasting overnight before dosing. Equal groups of seven rats were used in all experiments.

\section{Drugs and chemicals}

Copper acetate monohydrate was obtained from Sigma Aldrich (Schnelldorf, Germany), and indomethacin (Indocid ${ }^{\circledR}$ ) was obtained from Merck (Darmstadt, Germany). Copper indomethacin $\left[\mathrm{Cu}_{2}-(\text { Indo })_{4}\left(\mathrm{OH}_{2}\right)_{2}\right] \cdot 1.5 \mathrm{H}_{2} \mathrm{O}$ was synthesized as reported in Weder et al. ${ }^{7}$ For gel preparation, $1 \mathrm{~g} \mathrm{Cu}$-Indo was dissolved in 30 g Cremophor RH 40 (BASF, Ludwigshafen, Germany) at $60^{\circ} \mathrm{C}$ for 15 minutes, and then $0.25 \mathrm{~g}$ methyl paraben and $0.15 \mathrm{~g}$ propyl paraben were added to the mixture (Salicylates and Chemicals Pvt. Ltd., India), and $1.5 \mathrm{~g}$ carbopol 934 (Lubrizol, Germany) was dispersed in water and added to the Cremophor mixture. Final weight was adjusted to $100 \mathrm{~g}$ by addition of water. $\mathrm{NaOH}(18 \%)$ was used to adjust the PH.

\section{Induction of osteoarthritis}

Osteoarthritis was induced by the intracapsular injection of $50 \mu \mathrm{L}$ with $40 \mathrm{mg} / \mathrm{mL}$ MIA through the infrapatellar ligament, as described by Guingamp et al, ${ }^{8}$ Guzman et al, ${ }^{9}$ and Vermeirsch et al. ${ }^{10} \mathrm{~A}$ sham group was subjected to the same injection procedure, but with $50 \mu \mathrm{L}$ of normal saline solution.

\section{Interventions}

Rats with induced OA were randomly assigned 1 week after injection into five groups: an untreated OA group, an active control group treated with a daily dose of $1 \mathrm{~g} / \mathrm{kg}$ of topical $1 \%$ indomethacin gel (corresponding to $10 \mathrm{mg} / \mathrm{kg}$ of the active substance) for 3 weeks, and three experimental groups treated with topical $1 \% \mathrm{Cu}$-Indo gel in three different daily doses, one of which was given a dose equivalent to the active comparator $1 \mathrm{~g} / \mathrm{kg}$ of the gel, and the two others of which were treated with lower doses ( 0.5 and $0.25 \mathrm{~g} / \mathrm{kg}$ daily), all for 3 weeks' duration. Sham group was topically treated with $1 \mathrm{~g} / \mathrm{kg}$ of the inactive vehicle gel.

\section{Outcome measures}

At the end of the 3 weeks of treatment, anti-inflammatory efficacy was assessed in all treated groups by measurement of serum inflammatory cytokines: interleukins 6 and 8 (IL-6 and IL-8), tumor necrosis factor-alpha (TNF- $\alpha$ ), and the weekly assessment of knee joint swelling, using a digital caliber for knee diameter measurement. Joint mobility, motor function, and ambulatoryevoked pain were assessed in this study once weekly by the accelerating rotarod apparatus (Ugo Basile, Varese, Italy, Model 7750), according to Vonsy et al. ${ }^{11}$ In addition, histopathologic examination of the affected knee (femorotibial joint) was performed. The safety of the topical application of $\mathrm{Cu}$-Indo $(0.25$, 0.5 , and $1 \mathrm{~g} / \mathrm{kg}$ ) for up to 3 months to rats' skin was determined by estimation of a complete blood count, liver and kidney function, and histopathologic examination for target tissues.

\section{Statistical analysis}

Statistical analysis of results was performed using SPSS statistics package version 17.0 (SPSS, Chicago, IL, USA). 
Table I Dunnett multicomparison test for serum markers in osteoarthritis group versus the normal and sham groups

\begin{tabular}{|c|c|c|c|c|}
\hline $\begin{array}{l}\text { Dependent variable and } \\
\text { (I) control groups }\end{array}$ & $\begin{array}{l}\text { (J) Untreated induced } \\
\text { OA group }\end{array}$ & $\begin{array}{l}\text { Mean difference } \\
(I, J)\end{array}$ & $\begin{array}{l}\text { Standard } \\
\text { error }\end{array}$ & Significance \\
\hline \multicolumn{5}{|l|}{ Interleukin 6} \\
\hline Normal & Induced OA & $-15.83 *$ & 2.88 & $0.000 *$ \\
\hline Sham & Induced OA & $-8.55^{*}$ & 2.88 & $0.011 *$ \\
\hline \multicolumn{5}{|l|}{ Interleukin 8} \\
\hline Normal & Induced OA & $-38.86 *$ & 16.38 & $0.032 *$ \\
\hline Sham & Induced OA & -18.17 & 16.38 & 0.232 \\
\hline \multicolumn{5}{|l|}{ Tumor necrosis factor } \\
\hline Normal & Induced OA & $-47.01 *$ & 6.85 & $0.000 *$ \\
\hline Sham & Induced OA & $-36.27^{*}$ & 6.85 & $0.000 *$ \\
\hline
\end{tabular}

Notes: *Mean difference is significant at the 0.05 level. Dunnett's test treat one group as a control (J), and compare all other groups (I) against it. Abbreviation: OA, osteoarthritis.

Values were expressed as means \pm standard deviation. Quantitative differences between values were statistically analyzed by one-way analysis of variance, followed by Tukey or Dunnett post hoc tests for multiple intergroup comparisons. Two dependent groups were compared by paired sample $t$-test. A $P$-value of $<0.05$ was considered to be statistically significant.

\section{Results}

\section{Assessment of IL-6, IL-8, and TNF- $\alpha$ serum levels}

To evaluate our induced rat model; we initially compared the changes in the selected inflammatory cytokines in the induced OA (untreated) rat model versus both normal and sham rat groups (as control groups) by Dunnett multicomparison statistical test. IL-6 and TNF- $\alpha$ serum levels were found to be highly significantly elevated in the untreated induced osteoarthritic group in comparison with both the sham and normal rat groups, whereas IL- 8 was significantly elevated compared with the normal rat group, and less markedly elevated than the sham group (Table 1).

After the duration of 3 weeks of daily treatment, $\mathrm{Cu}$-Indo gel at the three examined dose levels and indomethacin (active control group) resulted in a significant decrease of the elevated serum IL-6 compared with in the untreated OA group. In addition, the lowest dose $(0.25 \mathrm{~g} / \mathrm{kg})$ of gel showed the greatest decrease in serum IL-6 level in comparison to all other treatment groups, including the higher doses of $\mathrm{Cu}$ Indo, but this did not reach statistical significance by Tukey post hoc multicomparisons test (Tables 2 and 3). Serum IL-8 was significantly decreased in $\mathrm{Cu}-$ Indo gel, at doses of 0.25 and $0.5 \mathrm{~g} / \mathrm{kg}$, compared with in the untreated OA group. However, $\mathrm{Cu}-\mathrm{Indo}$ gel at a dose of $1 \mathrm{~g} / \mathrm{kg}$ and the indomethacin group failed to decrease the elevated serum IL-8 level.

Table 2 One-way analysis of variance test for comparison of treatment effect on inflammatory cytokines

\begin{tabular}{|c|c|c|c|c|c|}
\hline Studied Cytokines \& Treatment groups & $\mathbf{N}$ & Mean & Standard deviation & $F$ & Significance \\
\hline \multicolumn{6}{|l|}{ Interleukin 8} \\
\hline Induced OA (not treated) & 5 & 193.60 & 17.47 & 21.58 & $<0.001$ \\
\hline Cu-Indo I g/kg & 5 & 159.63 & 35.49 & & \\
\hline Cu-Indo $0.5 \mathrm{~g} / \mathrm{kg}$ & 5 & 143.65 & 13.96 & & \\
\hline Cu-Indo $0.25 \mathrm{~g} / \mathrm{kg}$ & 5 & 71.27 & 14.95 & & \\
\hline Indomethacin I g/kg & 5 & 164.63 & 21.11 & & \\
\hline \multicolumn{6}{|l|}{ Interleukin 6} \\
\hline Induced OA (not treated) & 5 & 83.08 & 6.70 & 10.58 & $<0.001$ \\
\hline Cu-Indo I g/kg & 5 & 71.69 & 4.83 & & \\
\hline Cu-Indo $0.5 \mathrm{~g} / \mathrm{kg}$ & 5 & 67.93 & 5.54 & & \\
\hline Cu-Indo $0.25 \mathrm{~g} / \mathrm{kg}$ & 5 & 62.35 & 3.80 & & \\
\hline Indomethacin I g/kg & 5 & 69.07 & 4.99 & & \\
\hline \multicolumn{6}{|l|}{ Tumor necrosis factor } \\
\hline Induced OA (not treated) & 5 & $|24.7|$ & 10.64 & 11.48 & $<0.001$ \\
\hline Cu-Indo I g/kg & 5 & 86.42 & 10.65 & & \\
\hline Cu-Indo $0.5 \mathrm{~g} / \mathrm{kg}$ & 5 & 93.96 & 9.08 & & \\
\hline Cu-Indo 0.25 g/kg & 5 & 93.01 & 9.47 & & \\
\hline Indomethacin I g/kg & 5 & 106.43 & 10.13 & & \\
\hline
\end{tabular}

Note: The bold figures represent the significantly different group (in posthoc Tukey tests).

Abbreviation: OA, osteoarthritis; Cu-Indo, copper indomethacin. 
Table 3 Post hoc Tukey HSD* test for intergroup comparisons of interleukin 6

\begin{tabular}{|c|c|c|c|}
\hline \multirow[t]{2}{*}{ Treatment group } & \multirow[t]{2}{*}{$\mathbf{N}$} & \multicolumn{2}{|c|}{$\begin{array}{l}\text { Subset for alpha } \\
=0.05\end{array}$} \\
\hline & & $\mathbf{I}$ & 2 \\
\hline Cu-Indo $0.25 \mathrm{~g} / \mathrm{kg}$ & 5 & 62.35 & \\
\hline Cu-Indo $0.5 \mathrm{~g} / \mathrm{kg}$ & 5 & 67.93 & \\
\hline Indomethacin I g/kg & 5 & 69.07 & \\
\hline Cu-Indo I g/kg & 5 & 71.69 & \\
\hline Induced osteoarthritis (untreated) & 5 & & 83.08 \\
\hline Significance & & 0.07 & 1.00 \\
\hline
\end{tabular}

In addition, the lowest dose of $\mathrm{Cu}$-Indo $(0.25 \mathrm{~g} / \mathrm{kg})$ was significantly superior to all other treatments, including the higher doses of $\mathrm{Cu}$-Indo, in reducing the serum IL-8 level (Table 2 and 4).

In contrast, $\mathrm{Cu}$-Indo gel at all studied doses $(0.25,0.5$, and $1 \mathrm{~g} / \mathrm{kg}$ ) was significantly superior to indomethacin gel at $1 \mathrm{~g} / \mathrm{kg}$ dose to decrease the serum TNF- $\alpha$ level (Tables 2-5).

\section{Assessment of knee joint edema percentage}

Joint swelling or edema percentage was manifested after induction of $\mathrm{OA}$ in comparison to the normal control joint. All treatment groups, including the three doses of $\mathrm{Cu}$-Indo, as well as indomethacin gel, showed a significantly lower knee joint swelling than the untreated osteoarthritic group after the 2nd week of treatment. After the 1st week, the group treated with $\mathrm{Cu}$ Indo gel $1 \mathrm{~g} / \mathrm{kg}$ was the only group to have a significantly lower percentage of edema than the untreated OA group (Table 6).

\section{Assessment of joint mobility, pain, and motor coordination}

Induction of OA using MIA resulted in significant decrease in the duration of rotations of rats on the rotarod apparatus, indicating the decrease of their joint motor function,

Table 4 Post hoc Tukey HSD test for intergroup comparisons of interleukin 8

\begin{tabular}{lllll}
\hline Treatment group & N & \multicolumn{3}{c}{ Subset for alpha $=\mathbf{0 . 0 5}$} \\
\cline { 2 - 5 } & & $\mathbf{I}$ & $\mathbf{2}$ & $\mathbf{3}$ \\
\hline Cu-Indo $0.25 \mathrm{~g} / \mathrm{kg}$ & 5 & $\mathbf{7 1 . 2 7}$ & & \\
Cu-Indo $0.5 \mathrm{~g} / \mathrm{kg}$ & 5 & & $\mathbf{1 4 3 . 6 5}$ & \\
Cu-Indo I g/kg & 5 & & 159.63 & 159.63 \\
Indomethacin I g/kg & 5 & & 164.63 & 164.63 \\
Induced osteoarthritis (untreated) & 5 & & & 193.60 \\
Significance & & 1.00 & 0.57 & 0.15 \\
\hline
\end{tabular}

Note: The bold figures represent significantly different means.

Abbreviations: Cu-Indo, copper indomethacin; HSD, honest significant difference.
Table 5 Post hoc Tukey HSD* test for intergroup comparisons of TNF- $\alpha$

\begin{tabular}{|c|c|c|c|c|}
\hline \multirow[t]{2}{*}{ Treatment group } & \multirow[t]{2}{*}{$\mathbf{N}$} & \multicolumn{3}{|c|}{ Subset for alpha $=0.05$} \\
\hline & & $\mathbf{I}$ & 2 & 3 \\
\hline Cu-Indo I g/kg & 5 & 86.42 & & \\
\hline Cu-Indo $0.25 \mathrm{~g} / \mathrm{kg}$ & 5 & 93.01 & 93.01 & \\
\hline Cu-Indo $0.5 \mathrm{~g} / \mathrm{kg}$ & 5 & 93.96 & 93.96 & \\
\hline Indomethacin I g/kg & 5 & & 106.43 & 106.43 \\
\hline Induced osteoarthritis (untreated) & 5 & & & | 24.7 | \\
\hline Significance & & 0.757 & 0.251 & 0.062 \\
\hline
\end{tabular}

Notes: Means for groups in homogeneous subsets at $5 \%$ level of significance are displayed. *Uses harmonic mean sample size $=5.000$. The bold figures represent significantly different means.

Abbreviations: $\mathrm{Cu}-$ Indo, copper indomethacin; HSD, honest significant difference; TNF- $\alpha$, tumor necrosis factor-alpha.

mobility, and ability to stay on the rotating spindle, related to their actively inflamed, swollen, stiff, and painful joints.

During the entire period of the experiment, the $\mathrm{Cu}$-Indo gel-treated group, at a dose of $0.25 \mathrm{~g} / \mathrm{kg}$, was the only group that showed significant improvement of mobility

Table 6 Tukey HSD for intergroup comparisons of percentage edema

\begin{tabular}{|c|c|c|c|}
\hline \multirow[t]{2}{*}{ Week and treatment group } & \multirow[t]{2}{*}{$\mathbf{N}$} & \multicolumn{2}{|c|}{$\begin{array}{l}\text { Subset for alpha } \\
=0.05\end{array}$} \\
\hline & & $\mathbf{I}$ & 2 \\
\hline \multicolumn{4}{|l|}{ At week I } \\
\hline Cu-Indo I g/kg & 5 & 16.013 & \\
\hline Indomethacin I g/kg & 5 & 16.81 & 16.81 \\
\hline Cu-Indo $0.5 \mathrm{~g} / \mathrm{kg}$ & 5 & 16.90 & 16.90 \\
\hline Cu-Indo $0.25 \mathrm{~g} / \mathrm{kg}$ & 5 & 16.91 & 16.91 \\
\hline Induced osteoarthritis (not treated) & 5 & & 22.091 \\
\hline Significance & & 0.99 & 0.067 \\
\hline \multicolumn{4}{|l|}{ At week 2} \\
\hline Cu-Indo $0.25 \mathrm{~g} / \mathrm{kg}$ & 5 & 16.128 & \\
\hline Cu-Indo I g/kg & 5 & 16.168 & \\
\hline Cu-Indo $0.5 \mathrm{~g} / \mathrm{kg}$ & 5 & 16.872 & \\
\hline Indomethacin I g/kg & 5 & 18.8743 & \\
\hline Induced osteoarthritis (not treated) & 5 & & 29.03 \\
\hline Significance & & 0.642 & 1.00 \\
\hline \multicolumn{4}{|l|}{ At week 3} \\
\hline Cu-Indo I g/kg & 5 & 17.99 & \\
\hline Cu-Indo 0.5 g/kg & 5 & 18.14 & \\
\hline Cu-Indo $0.25 \mathrm{~g} / \mathrm{kg}$ & 5 & 18.86 & \\
\hline Indomethacin I g/kg & 5 & 19.82 & \\
\hline Induced osteoarthritis (not treated) & 5 & & 28.59 \\
\hline Significance & & 0.84 & 1.00 \\
\hline \multicolumn{4}{|l|}{ At week 4} \\
\hline Cu-Indo $0.5 \mathrm{~g} / \mathrm{kg}$ & 5 & 16.595 & \\
\hline Cu-Indo I g/kg & 5 & 17.31 & \\
\hline Indomethacin I g/kg & 5 & 17.54 & \\
\hline Cu-Indo $0.25 \mathrm{~g} / \mathrm{kg}$ & 5 & 19.438 & \\
\hline Induced osteoarthritis (not treated) & 5 & & 27.635 \\
\hline Significance & & 0.324 & 1.00 \\
\hline
\end{tabular}

Notes: Means for groups in homogeneous subsets at $5 \%$ significance level are displayed. The bold figures represent significantly different means.

Abbreviations: Cu-Indo, copper indomethacin; HSD, honest significant difference. 
Table 7 Tukey HSD for intergroup comparisons of rotation in seconds at week I

\begin{tabular}{llll}
\hline Treatment group & $\mathbf{N}$ & \multicolumn{2}{l}{$\begin{array}{l}\text { Subset for alpha } \\
=\mathbf{0 . 0 5}\end{array}$} \\
\cline { 3 - 4 } & & $\mathbf{I}$ & $\mathbf{2}$ \\
\hline Cu-Indo $0.5 \mathrm{~g} / \mathrm{kg}$ & 5 & 127.20 & \\
Cu-Indo I g/kg & 5 & 135.20 & \\
Induced osteoarthritis (not treated) & 5 & 137.40 & \\
Indomethacin I g/kg & 5 & 152.20 & 152.20 \\
Cu-Indo $0.25 \mathrm{~g} / \mathrm{kg}$ & 5 & & $\mathbf{1 7 0 . 0 0}$ \\
Significance & & 0.174 & 0.476 \\
\hline
\end{tabular}

Note: The bold figure represent a significantly different mean.

Abbreviations: $\mathrm{Cu}$-Indo, copper indomethacin; HSD, honest significant difference.

and prolongation of the duration on the rotarod apparatus in seconds compared with the untreated OA group. This can indicate, in our model of arthritis, improvements in joint mobility, motor function, and less ambulatory-evoked pain (better analgesia) in that group. Moreover, the active comparison group treated with indomethacin gel showed a significant increase in the duration of rotation only after 3 weeks of treatment (Tables 7-9).

\section{Assessment of knee joint histopathology}

A histopathology study of knee joints (Figures 1-8) revealed widening in the space of the joint in the osteoarthritic group compared with normal, with the presence of fine collagenous fibers and the presence of fibrous tissue on the upper surface of the cartilage. Rats treated with $\mathrm{Cu}$-Indo gel at a dose of $0.25 \mathrm{~g} / \mathrm{kg}$ showed improvement of the joint structure, but there is a noticeable thinning of the cartilage of the joint, which is more marked on one side than the other. In contrast, the dose $(0.5 \mathrm{~g} / \mathrm{kg})$ showed widening in the synovial space of the joint denoting edema. Moreover, the cartilage on one side of the joint shows thinning, with reduction of chondroblast layer thickness on both sides of the joint. Treatment with $\mathrm{Cu}$-Indo gel in a dose of $1 \mathrm{~g} / \mathrm{kg}$ resulted in discontinuity of the upper smooth surface of the cartilage at many places,

Table 8 Tukey HSD for intergroup comparisons of rotation in seconds at week 2

\begin{tabular}{llll}
\hline Treatment group & $\mathbf{N}$ & \multicolumn{2}{l}{$\begin{array}{l}\text { Subset for alpha } \\
=\mathbf{0 . 0 5}\end{array}$} \\
\cline { 3 - 4 } & & $\mathbf{I}$ & $\mathbf{2}$ \\
\hline Cu-Indo $0.5 \mathrm{~g} / \mathrm{kg}$ & 5 & 138.000 & \\
Cu-Indo I g/kg & 5 & 141.600 & \\
Induced osteoarthritis (not treated) & 5 & 142.400 & \\
Indomethacin I g/kg & 5 & 147.900 & 147.900 \\
Cu-Indo $0.25 \mathrm{~g} / \mathrm{kg}$ & 5 & & $\mathbf{1 5 7 . 4 0 0}$ \\
Significance & & 0.218 & 0.252 \\
\hline
\end{tabular}

Note: The bold figure represent a significantly different mean.

Abbreviations: Cu-Indo, copper indomethacin; HSD, honest significant difference.
Table 9 Tukey HSD for intergroup comparisons of rotation in seconds at week 3

\begin{tabular}{|c|c|c|c|c|}
\hline \multirow[t]{2}{*}{ Treatment group } & \multirow[t]{2}{*}{$\mathbf{N}$} & \multicolumn{3}{|c|}{ Subset for alpha $=0.05$} \\
\hline & & I & 2 & 3 \\
\hline Induced osteoarthritis (not treated) & 5 & 121.20 & & \\
\hline Cu-Indo I g/kg & 5 & 136.00 & 136.00 & \\
\hline Cu-Indo $0.5 \mathrm{~g} / \mathrm{kg}$ & 5 & 139.00 & 139.00 & \\
\hline Indomethacin I g/kg & 5 & & 150.40 & 150.40 \\
\hline Cu-Indo $0.25 \mathrm{~g} / \mathrm{kg}$ & 5 & & & 169.00 \\
\hline Significance & & 0.282 & 0.483 & 0.244 \\
\hline
\end{tabular}

although the synovial space is of normal width and the thickness of the cartilage is more or less normal.

\section{Assessment of safety}

After 3 months of daily application, there were no notable changes in studied safety parameters in the group treated with the lowest $\mathrm{Cu}$-Indo dose $(0.25 \mathrm{~g} / \mathrm{kg}$ daily), but the group treated with the higher dose $(1 \mathrm{~g} / \mathrm{kg})$ showed a slight but significant increase in serum unconjugated bilirubin and a slight decrease in hemoglobin and red blood cell count, with normal indices denoting a slight hemolytic effect at the high copper dose.

\section{Discussion}

Our overall results can indicate that at lower doses, $\mathrm{Cu}$-Indo gel can be superior to, or at least as effective as, its parent substance indomethacin in most of the studied parameters of inflammation in the OA rat model. In fact, the lowest tested dose of $\mathrm{Cu}-\mathrm{Indo}$, corresponding to $25 \%$ of the parent substance indomethacin, showed the highest superiority in reducing the

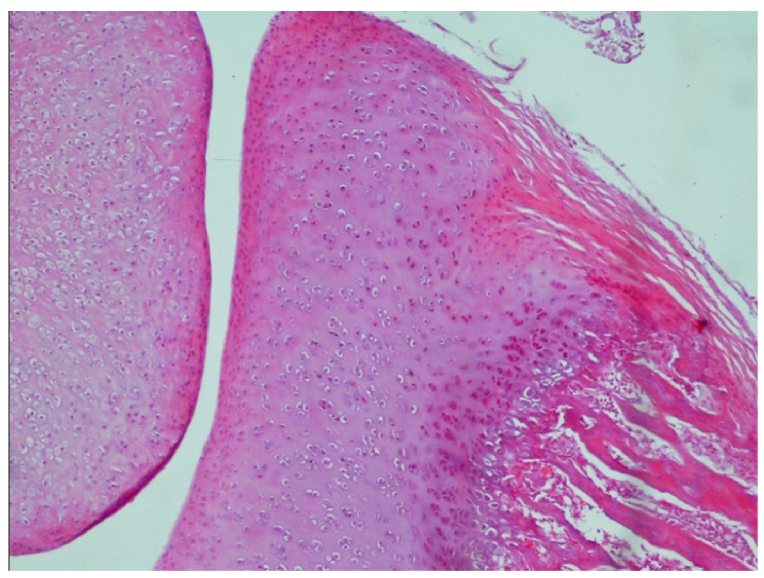

Figure I Photomicrograph of a knee joint from a control rat showing the normal structure of this joint. The upper surface of the cartilage is smooth, the chondroblasts (near the upper surface) are small and flattened, and the chondrocytes (below) are rounded, large, and enclosed in lacunae (H\&E stain, $\times 100)$.

Abbreviation: H\&E, Haematoxylin \& Eosin. 


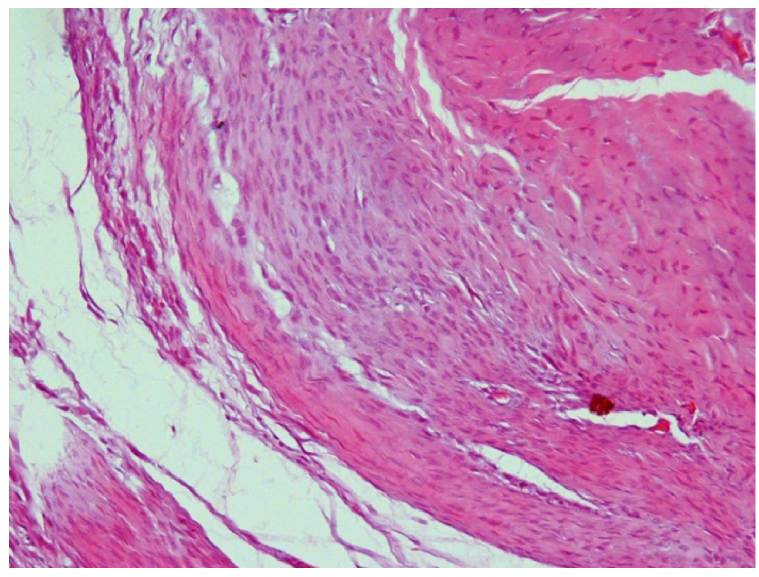

Figure 2 Photomicrograph of a knee joint from an osteoarthritic-induced rat model, showing widening in the space of the joint compared to normal, with the presence of fine collagenous fibers. The upper surface of the cartilage is rough because of the presence of fibrous tissue. The main bulk of the cartilage is formed of chondroblasts (H\&E stain, $\times 100$ ).

Abbreviation: H\&E, Haematoxylin \& Eosin.

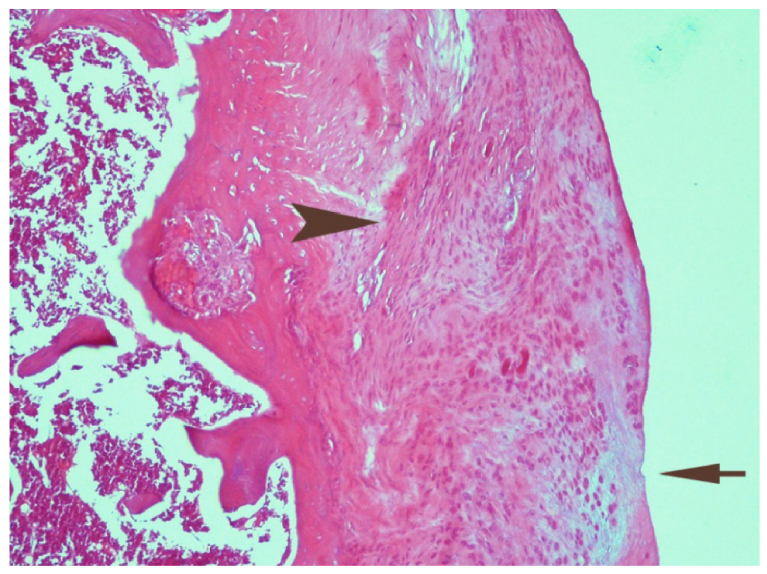

Figure 3 Photomicrograph of a knee joint from a rat treated with indomethacin, showing irregularity in the upper surface of the cartilage (arrow), fibrous elements in the cartilage (arrow head), and small abnormal chondrocytes (H\&E stain, $\times 100$ ).

Abbreviation: H\&E, Haematoxylin \& Eosin.

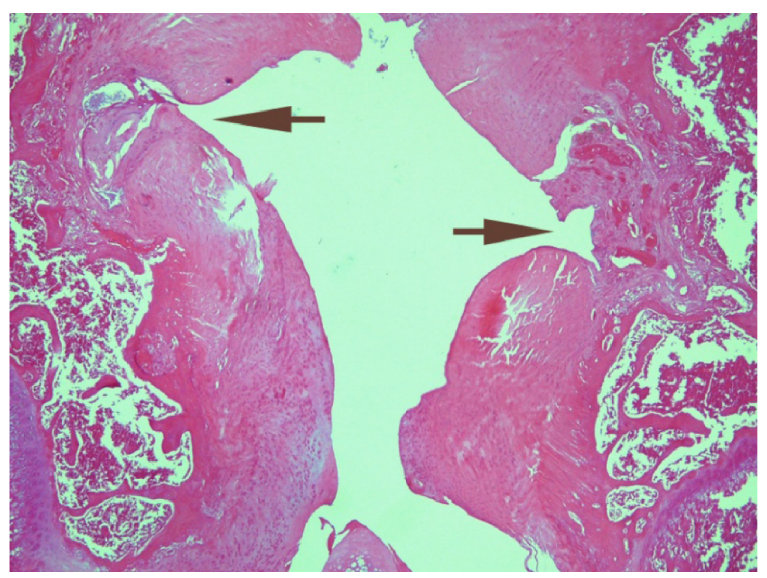

Figure 4 Photomicrograph of a knee joint from a rat treated with indomethacin, showing severe irregularity in the upper surface of the cartilage making notches (arrow) at the left side; the right side shows ulceration of the cartilage with granulation tissue filling the gap. The thickness of the cartilage is not uniform (H\&E stain, $\times 100$ ). Abbreviation: H\&E, Haematoxylin \& Eosin.
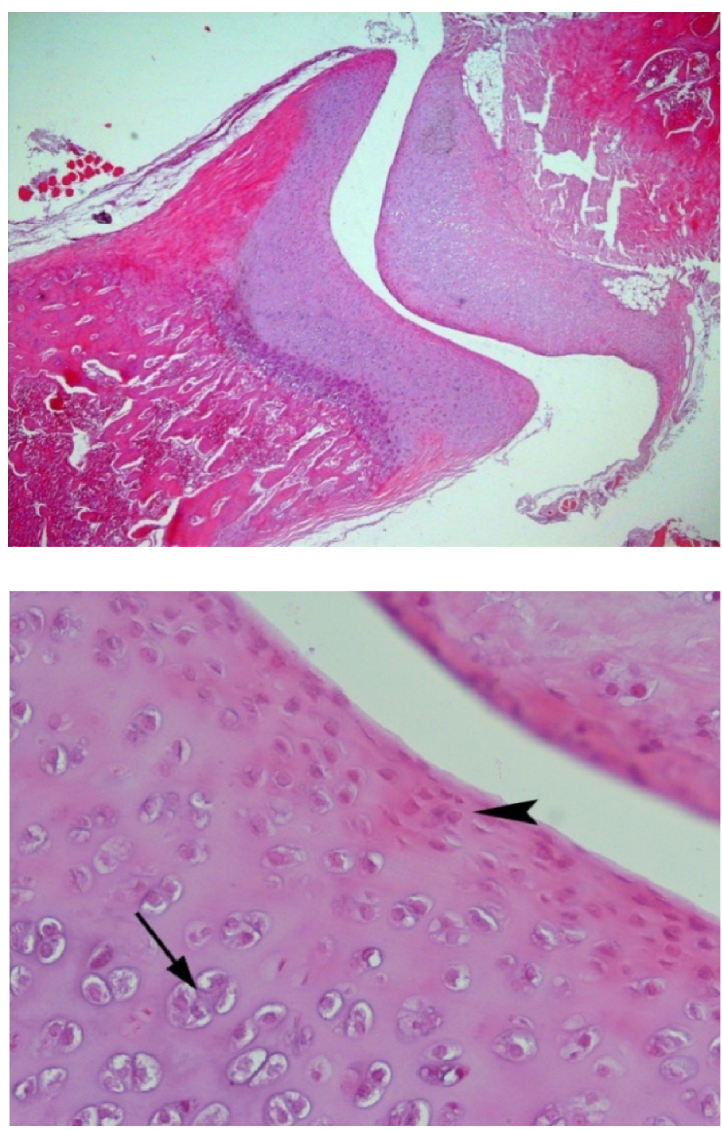

Figure 5 A photomicrograph of a knee joint from a sham rat, showing a quite normal structure of knee joint by low magnification at the top figure. The bottom figure shows a higher magnification of the same section. Notice the smooth surface of the cartilage on both sides of the synovial space that appears uniform and narrow. The upper part of the cartilage is formed of flattened chondroblasts (arrow head), whereas the deeper part is formed of mature chondrocytes that lie in groups of two or four in lacunae (arrow) (H\&E stain, $\times 50$ \& 200).

Abbreviation: H\&E, Haematoxylin \& Eosin.

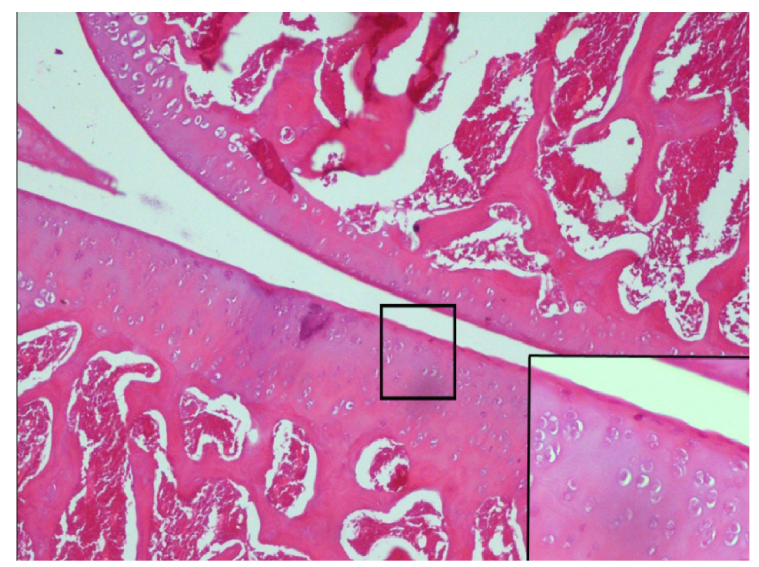

Figure 6 Photomicrograph of a knee joint from a rat treated with $\mathrm{Cu}$ indomethacin gel in a dose of $0.25 \mathrm{~g} / \mathrm{kg}$, showing a remarkable amelioration of the joint structure. The synovial space is narrow and uniform, but there is a noticeable thinning of the cartilage of the joint, which is more marked on one side than the other. The part of the figure at bottom right shows a higher magnification of a part of the section, where the thickness of the chondroblast layer is greatly reduced. The chondrocytes are abnormal in shape and appear individually in their lacunae, denoting abnormal capability of division (H\&E stain, $\times 100$ \& 200).

Abbreviation: H\&E, Haematoxylin \& Eosin. 


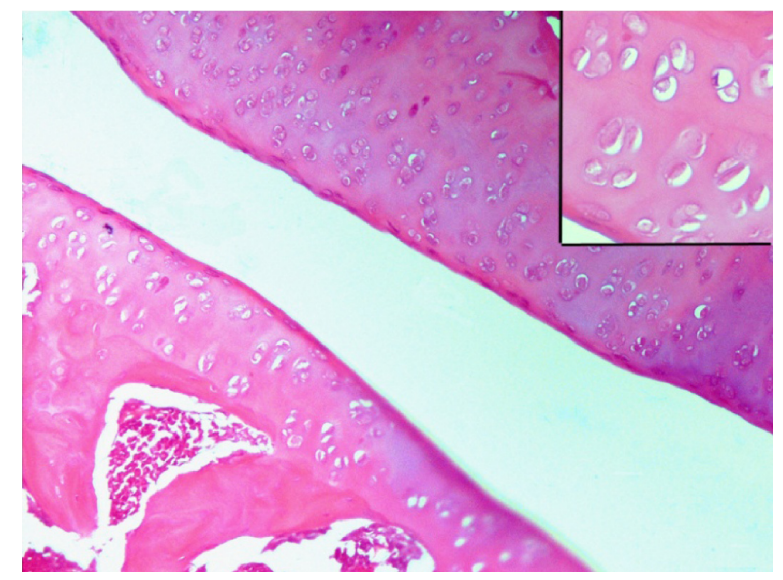

Figure 7 Photomicrograph of a knee joint from a rat treated with $\mathrm{Cu}$ indomethacin gel in a dose of $0.5 \mathrm{~g} / \mathrm{kg}$, showing widening in the synovial space of the joint denoting edema. The cartilage on one side of the joint shows thinning with reduction of chondroblast layer thickness on both sides of the joint. The upper right part of the figure is a higher magnification of a part of the section showing abnormal-shaped chondrocytes (H\&E stain, $\times 100$ \& 200).

Abbreviation: H\&E, Haematoxylin \& Eosin.

elevated serum-tested ILs and in increasing the time duration on the rotarod test, whereas its effect on reduction of edema and TNF- $\alpha$ was comparable to that of the others.

This can be explained by the observation reported by many authors that copper complexes of NSAIDs are more active than these drugs by themselves. This can be partially explained by the assumption made by many authors ${ }^{12-16}$ that copper complexes in low dose can provide a superoxide dismutase-like action that could readily cross the cell membranes and be capable of reaching intracellular superoxide-generating sites, leading to the inactivation of the highly reactive oxygen radicals, superoxide, and hydroxyl

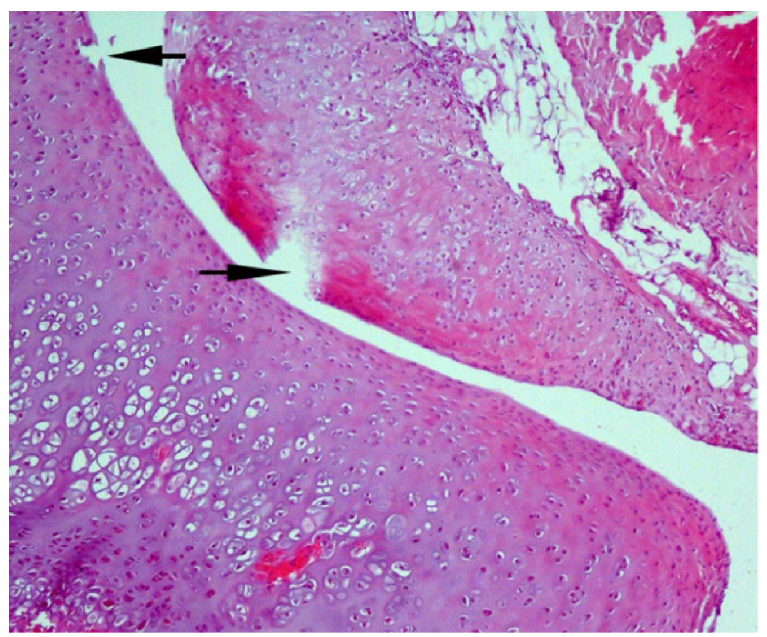

Figure 8 Photomicrograph of a knee joint from a rat treated with $\mathrm{Cu}$ indomethacin gel in a dose of $\mathrm{I} g / \mathrm{kg}$, showing discontinuity of the upper smooth surface of the cartilage at many places (arrow), although the synovial space is of normal width and the thickness of the cartilage is more or less normal (H\&E stain, $\times 100)$. Abbreviation: H\&E, Haematoxylin \& Eosin. radicals, and that copper ions can be directly transferred from the complex into the copper binding site of the $\mathrm{Cu}-\mathrm{Zn}$ superoxide dismutase enzyme to activate it. Through this mechanism, we can propose that the $\mathrm{Cu}$-Indo complex can indirectly reduce the activation of NF kappa B and perhaps other inflammatory transcription factors, thereby preventing up-regulation of inflammatory cytokine production. This may be the reason why the lowest dose of $\mathrm{Cu}-\mathrm{Indo}(0.25 \mathrm{~g} / \mathrm{kg})$ was associated with a marked and significant decrease of the levels of studied ILs (IL-6 and IL-8) compared with the higher dose of the parent molecule indomethacin.

This mechanism may become less efficient at higher doses of copper, as the increased levels of free copper irons beyond the antioxidant capacity can exert a prooxidant action via a Fenton-like mechanism.

Also, as reported by Okuyama et $a 1{ }^{17} \mathrm{Cu}(\mathrm{II}) 2$ (indomethacin) 4 was found to be a more effective analgesic than its parent ligand and to be as effective as morphine in rat pain models. They hypothesized that copper complexes activate copper-dependent opioid receptors, which could explain in part the markedly increased duration at the rotarod test through not only the markedly higher anti-inflammatory activity but also the potent analgesic efficacy.

\section{Conclusion}

$\mathrm{Cu}$-Indo gel has a potent anti-inflammatory activity against joint inflammation in the MIA-treated rat model of OA at doses of $0.25,0.5$, and $1 \mathrm{~g} / \mathrm{kg}$. The lowest dose was better both in terms of both safety and efficacy parameters.

\section{Disclosure}

The authors report no conflicts of interest in this work.

\section{References}

1. National Institute for Health and Clinical Excellence. Osteoarthritis: The Care and Management of Osteoarthritis in Adults. NICE Clinical Guideline 59. London: National Institute for Health and Clinical Excellence; 2008. Available from: http://www.nice.org.uk/nicemedia/ pdf/CG59NICEguideline.pdf. Accessed March 12, 2012.

2. Stanos S. Osteoarthritis guidelines: a progressive role for topical NSAIDs. J Am Osteopath Assoc. 2013;113(2):123-127.

3. Brady SJ, Brooks P, Conaghan P, Kenyon LM. Pharmacotherapy and osteoarthritis. Baillieres Clin Rheumatol. 1997;11(4):749-768.

4. Milanino R, Conforti A, Franco L, Marrella M, Velo G. Copper and inflammation - a possible rationale for the pharmacological manipulation of inflammatory disorders. Agents Actions. 1985;16(6):504-513.

5. Bilgin MD, Elçin AE, Elçin YM. Topical use of liposomal copper palmitate formulation blocks porphyrin-induced photosensitivity in rats. J Photochem Photobiol B. 2005;80(2):107-114.

6. Bonin AM, Yáñez JA, Fukuda C, et al. Inhibition of experimental colorectal cancer and reduction in renal and gastrointestinal toxicities by copper-indomethacin in rats. Cancer Chemother Pharmacol. 2010;66(4): $755-764$. 
7. Weder JE, Hambley TW, Kennedy BJ, et al. Anti-Inflammatory Dinuclear Copper(II) Complexes with Indomethacin. Synthesis, Magnetism and EPR Spectroscopy. Crystal Structure of the N,N-Dimethylformamide Adduct. Inorg Chem. 1999;38(8): 1736-1744.

8. Guingamp C, Gegout-Pottie P, Philippe L, Terlain B, Netter P, Gillet P. Mono-iodoacetate-induced experimental osteoarthritis: a dose-response study of loss of mobility, morphology, and biochemistry. Arthritis Rheum. 1997;40(9):1670-1679.

9. Guzman RE, Evans MG, Bove S, Morenko B, Kilgore K. Monoiodoacetate-induced histologic changes in subchondral bone and articular cartilage of rat femorotibial joints: an animal model of osteoarthritis. Toxicol Pathol. 2003;31(6):619-624.

10. Vermeirsch H, Biermans R, Salmon PL, Meert TF. Evaluation of pain behavior and bone destruction in two arthritic models in guinea pig and rat. Pharmacol Biochem Behav. 2007;87(3):349-359.

11. Vonsy JL, Ghandehari J, Dickenson AH. Differential analgesic effects of morphine and gabapentin on behavioural measures of pain and disability in a model of osteoarthritis pain in rats. Eur J Pain. 2009;13(8):786-793.
12. Rubner G, Bensdorf K, Wellner A, Bergemann S, Gust R. Synthesis, characterisation and biological evaluation of copper and silver complexes based on acetylsalicylic acid. Arch Pharm (Weinheim). 2011; 344(10):684-688.

13. Barik A, Mishra B, Shen L, et al. Evaluation of a new copper(II)curcumin complex as superoxide dismutase mimic and its free radical reactions. Free Radic Biol Med. 2005;39(6):811-822.

14. Sorenson JR, Oberley LW, Crouch RK, et al. Pharmacologic activities of copper compounds in chronic diseases. Biol Trace Elem Res. 1983; 5(4-5):257-273.

15. Weser U, Sellinger KH, Lengfelder E, Werner W, Strähle J. Structure of $\mathrm{Cu} 2$ (indomethacin) 4 and the reaction with superoxide in aprotic systems. Biochim Biophys Acta. 1980;631(2):232-245.

16. Hamada T. Antioxidant and prooxidant roles of copper in Tween 20 -induced hemolysis of hamster and pig erythrocytes containing marginal vitamin E. Experientia. 1995;51(6):572-576.

17. Okuyama S, Hashimoto S, Aihara H, Willingham WM, Sorenson JR. Copper complexes of non-steroidal antiinflammatory agents: analgesic activity and possible opioid receptor activation. Agents Actions. 1987; 21(1-2):130-144.
Drug Design, Development and Therapy

\section{Publish your work in this journal}

Drug Design, Development and Therapy is an international, peerreviewed open-access journal that spans the spectrum of drug design and development through to clinical applications. Clinical outcomes, patient safety, and programs for the development and effective, safe, and sustained use of medicines are a feature of the journal, which

\section{Dovepress}

has also been accepted for indexing on PubMed Central. The manuscript management system is completely online and includes a very quick and fair peer-review system, which is all easy to use. Visit http://www.dovepress.com/testimonials.php to read real quotes from published authors.

Submit your manuscript here: http://www.dovepress.com/drug-design-development-and-therapy-journal 